\title{
On English Translation of Chinese Diplomatic Discourses from the Perspective of Pragmatic Triadic Relations
}

\author{
Chen Yulian \\ South China Business College, Guangdong University of Foreign Studies, Guangzhou, China
}

\section{Email address:}

yulianchen2003@163.com

\section{To cite this article:}

Chen Yulian. On English Translation of Chinese Diplomatic Discourses from the Perspective of Pragmatic Triadic Relations. International Journal of Applied Linguistics and Translation. Vol. 7, No. 2, 2021, pp. 53-58. doi: 10.11648/j.ijalt.20210702.14

Received: April 14, 2021; Accepted: April 28, 2021; Published: May 14, 2021

\begin{abstract}
Translation is a special case of language use and a special way of communication that spans language, time and culture. Translation of diplomatic discourse is a complicated communicative activity in which numerous factors should be taken into consideration such as the speech style of the speaker, the situational context and the distinctions between the source language and the target language. The pragmatic triadic relation mode of relational pragmatics is beneficial for the translation of diplomatic discourses from Chinese to English, according to which, the translator, language and context interact with each other in the translation process and constitute a complete system. The translator plays a subjective role whose mastery of both the source language and the target language will affect his understanding of the source text and his ways of re-expression and recreation; the linguistic and cultural characteristics of the source language will to some extent influence the translator's selection of words and understanding of the speaker's intention; while the situational and cultural contextual factors such as time, space, participants, culture, customs and values will also have impacts on translation. Comprehensive consideration of all these aspects will produce appropriate and effective translation of a diplomatic discourse and promote the dissemination of Chinese culture.
\end{abstract}

Keywords: Translation, Diplomatic Discourse, Pragmatic Triadic Relations, Language, Context

\section{Introduction}

Diplomatic discourse is a special type of political discourse which has peculiar characteristics. It is a specific speech act of diplomatic entities, especially sovereign states, in the diplomatic context to expound the diplomatic idea, guiding ideology, strategic position, goal planning, policy implementation and so on in a specific period, and to reflect a country's ideology, political proposition and core interests. Diplomatic discourse is widely deemed as formal, conservative, accurate and persuasive, paying much attention to etiquette and method. It plays a very significant role in promoting international relations, delivering diplomatic ideology and establishing country image. However, diplomatic discourse in practical application is much more complex and subtle than the existing features summarized above. It varies from person to person and from thing to thing. According to the concrete situation, sometimes it needs to be precise, clear and direct; sometimes it needs to be tactful, tortuous and implicit. Since the main receivers of a diplomatic discourse are usually foreigners, the communication between the speaker and the hearers needs to be done through translation. Translation is a cross-cultural and bilingual communicative activity which is restricted by factors such as communicative situation, psychological cognition, language and social factors. Therefore, the translation of diplomatic discourse is by no means an easy task which should take into accounts the relations among language, context and the communicators. In recent years, despite the widespread interest in translation studies, many scholars at home and abroad have made some achievements in this field. However, most of the studies have some limitations and the existing linguistic research lacks theoretical depth. This paper, from the perspective of relational pragmatics, explores the translation process of diplomatic discourse and the interaction of various pragmatic factors. The discourses discussed in the paper are from the famous books of $\mathrm{Xi}$ Jinping: The Governance of China I [1], The Governance of China II [2] and The Governance of China III [3]. It is hoped that the study can provide insights into the complicated pragmatic process in 
verbal communication.

\section{Relational Pragmatics}

Relational pragmatics was advocated by Kopytko, R. and elaborated in his series of papers [4-6]. He thinks that relational pragmatics is a kind of Non-Cartesian pragmatics that consists of three basic components, namely, communicator, language and context. The three components are not independent from each other in speech communication. Contrarily, they constitute a complete and closely related system. In verbal communication, they form a kind of ternary relationship, that is, the relation between communicator and language, the relation between language and context, and the relation between communicator and context. These three factors, and the relationship among them, together restrict the pragmatic competence of language users. In other words, the main research object of relational pragmatics is a complete system composed of social psychology, social culture, linguistics and context; this theory is based on the relationship among communicator, language and context, and emphasizes the influence of social and cultural factors on verbal communication.

\subsection{Context in Pragmatics}

Context, as a very important concept in language research, refers to the subjective and objective environmental factors of linguistic or non-linguistic expressions, which are used to express a particular meaning in a particular situation; these factors include the social environment, natural environment, communicative environment and both sides of communication [7]. The pragmatic meaning of discourse is not the abstract meaning or the meaning outside the context, but the meaning embodied when discourse is used in a certain context. The concrete meaning of language cannot be determined without the factors such as the specific time, place, occasion, the person who uses language and the purpose of using language. Therefore, the influence of pragmatic context on the participants in language practice determines the meaning, form and suitability of discourse [8]. Generally, context can be classified into linguistic context and non-linguistic context. Linguistic context defines the semantic orientation of the discourse through the use of words, phrases and sentences. While non-linguistic context includes context of situation and context of culture; the former usually involves factors like subject, time, space and participants for communication whereas the latter refers to culture, politics, economy, customs and religions of a specific society. What should be emphasized is that linguistic context and non-linguistic context are definitely not isolated from each other. Linguistic context is the abstraction and symbolization of non-linguistic context, while non-linguistic context is the source and reflection of linguistic context. Concerning the role of context in translation, Newmark deems that context is the most significant factor in all translation activities [9]. In the process of translation, the translator must consider many pragmatic factors in the context, so as to effectively translate the various intentions expressed in the original text, in order to achieve the consistency between the effect of the original and the target readers. Translators and translation activity are not only restricted by context, but also influence and construct context [10].

\subsection{The Triadic Relations}

As mentioned before, the ternary relation in relational pragmatics is mainly composed of communicator, language and context. They influence the pragmatic competence of language users. The success of a speech act is based on the interaction between the three factors. Specifically, the communicator is the subject in speech, the language is the medium, and the context is the object. They are interrelated, interactive while at the meantime distinct from each other. The three-dimensional relationship between communicator and language, language and context, and communicator and context is always the focus of relational pragmatics. That communicators play a subjective role in the process of verbal communication is not naturally decided. On the contrary, it is the result of the interaction between factors of different systems such as heredity, biology, society, culture and so on. Language, as the medium of verbal communication, is indispensable. It is difficult for the communicator to carry out the communication successfully without using a certain language and connecting the relevant texts with various factors of context. And these contextual factors can regulate the pragmatic interpretation and the use of actual discourse. Therefore, language, as a medium, plays a vital role in the actual verbal communication. It is a carrier for the communicator to convey information to the other party in a particular situation, and also a precondition for the receiver to understand and respond to the information. In this way, the communicator, language, and context together constitute an inseparable system, an essential condition for successful communication. And concerning the translation of diplomatic discourse, this relation is mainly presented among the translator, language and context.

\section{The Translation of Diplomatic Discourse Based on the Triadic Relation Mode}

In the process of translation, the translator plays the role of the communicator, and the source language and the target language involved are the languages of communication. In translation, the translator serves as the subject, the source language and the target language are the medium, and the context is the object. The pragmatic triadic relation mode can help the translator understand the guiding significance of relational linguistics from a theoretical perspective and to better control these three elements in the process of translating, thus achieving successful and effective translation results.

\subsection{The Translator and Translation}

The translation of China's political discourses aims at 
publicizing China's achievements in politics, economy, culture, military affairs, science and technology, and expressing the views and positions of our Party and government on international issues, to disseminate the excellent traditional Chinese culture. Unlike internal reporting and communication, the target of external translation is foreign readers, whose ideology, values, ways of thinking, aesthetic preferences and cultural schemata are quite different from those of domestic audiences, therefore, the meaning of the same cultural symbols are often quite different for them. Translation of diplomatic discourses is a very complex communicative activity, which involves many factors, including the relationship between the communicators and language mentioned in the above triadic relation mode. The communicators mainly refer to the speaker, the listener and the translator. For the needs of communication, the speaker sends a certain message to the listener, and the translator, after processing it appropriately, transmits it to the listener in the target language. In this particular communication, the translator acts as a go-between, translating the message of the speaker to the listener. In other words, the translator, as the subject in the process of complicated translation communication, shoulders the responsibility of transmitting the source language information to the target language readers The listener responds to the information he or she receives from the translator. This pragmatic relationship is reciprocal and reflects certain features and functions, affecting the relationship between language and context, and that between communicators and context. Their main task in this communicative activity is to generate and induce semantic input, so that the generated or induced information can be pragmatically output in the context.

In this process, not only the speaker's aim of making the speech and his mastery of the source language will affect the features of the diplomatic discourse, the cultural background, the emotional proclivities and the translating purpose of the translator will exert great influence on his understanding of the source text and his way of translation. To a great extent, translation is not only a process of translation between languages, but also a process of understanding and expression. In the process of translation, the translator is supposed to fully understand the author and analyze the source text in order to reproduce the information in the target language to the maximum extent. However, owing to the differences of times, history and culture, the translator's horizon cannot be completely integrated with the original author's horizon, and he might not understand the original author's intention. This gives the translator absolute initiative; the translator has the right to recreate on the basis of understanding. Yet, due to the differences in the translators' environment, experience and cognitive ability of things and language, there are differences in their ways of understanding and re-expressing the source text [11]. Therefore, different translators might form different translations and how the translators deal with the thinking mode of the source text and the target language is of vital significance.

Example 1
打铁还需自身硬。我们的责任, 就是同全党同志一道, 坚持党要管党、从严治党,

This was part of a speech Mr. Xi made in 2012 when the new Politburo Standing Committee met with Chinese and foreign journalists. This sentence has attracted so much attention that various media has reported and commented on it, while they have translated this sentence in completely different ways. For instance, the on-site translator of the foreign ministry translated it into "to be turned into iron, the metal itself must be strong"; The Telegraph of Britain translated it into "to forge iron, you need a strong hammer"; $C N N$ of US translated it into "to forge iron, one must be strong", and The Brunei Times translated it into "to forge iron, the hammer must be strong". The diversified versions have revealed that the speaker and the translators from different press have different ways of expressing and thinking. What the speaker wanted to emphasize in that specific situation was that to address the problems and difficulties encountered, the party members must first of all conduct themselves honorably. However, due to different thoughts, views and emotional experiences, the translators have formed their own understanding of the original text, among which some seemed to have diverted from the intention of the speaker. In this case, it is suggested to put it this way through combining both literal translation and the metaphorical meaning of the sentence "to forge iron, one must be strong; to address the problems, we must first of all conduct ourselves honorably".

\subsection{Language and Translation}

The realization of translation mainly depends on language and depends on the translator's mastery of the source language and the target language. Language serves as the medium and is the carrier for the translator to convey the information to the reader in the process of translation, and is the prerequisite for the reader to understand the original information and give feedback. An accurate grasp of the language is reflected in all aspects of the translation, such as vocabulary, sentence structure and so on. In diplomatic discourse, the speaker also mainly expresses his intention or tries to achieve his goal through language. To some extent, the delivery of this intention depends on the proficiency of the speaker in the manipulation of language. Additionally, the speaker must make full use of various linguistic and contextual factors. What the speaker says is selectively expressed in the context [12] in order to realize his communicative intention. This involves the contextual dynamics of pragmatic relations. Context restricts the use of language, while language is properly expressed through the mastery of various contextual factors. In diplomatic speeches made by President Xi, many ancient Chinese proverbs and poems are used. Compared with modern Chinese, these ancient and classical expressions have prominent features such as the frequent use of monosyllabic words and the use of short and simple sentences. The translator must be familiar with the linguistic and stylistic features of English and Chinese in order to adapt to the needs of the source text. To understand the classical expressions, the translator is supposed to get familiar with their stylistic 
features and then choose the proper techniques to translate based on the context in which they are used. In addition, individual preference of the speaker should not be neglected. As known to all, $\mathrm{Xi}$ has always struck the right note with his plain and simple words in his speeches. Seeking brevity, being realistic and seeking novelty are the styles of Xi's speech and composition, while common people's words, ancient people's words and Chinese and foreign classics are the contents frequently appearing in his speech, thus making it resonate with the common people.

In reality, because of the characteristics of the ancient writing style and individual preferences, the relevant discourse is often natural and smooth like floating clouds and flowing water. If the translation is just conducted according to the literal meaning of the source text, it is easy to split its whole sense, or even misinterpret the original meaning. The author holds that the focus of the translation of classical Chinese into English should be on the whole and the text should be considered against the background of context, so as to reveal the implied textual cohesion in ancient Chinese, in accordance with the characteristics of English hypotaxis. Thus in translation, the translator needs to think carefully, choose appropriate words and make use of techniques like addition, reduction, part-of-speech conversion, sentence breaking and combining, and other means together, rather than sticking to the form of the original.

Example 2 盖有非常之功, 必待非常之人。人是科技创 新最关键的因素。

To accomplish extraordinary feats, we must wait for extraordinary persons.

In the source language, “待” implies active anticipation, yet "must wait for" in the target language has the implication of passive waiting. This kind of interpretation departs from the real intention of the speaker since it is known to all that in this context, $\mathrm{Xi}$ intends to emphasize the subjective initiative of talents. For this reason, the English word "expect" is suggested for the translation. The chosen words are truly effective only if they convey the desired message accurately and convincingly, in a way that is relevant to the rhetorical situation, to the audience and to the purpose [13].

Example 3 天地之大, 黎元为本。

In a country, the people are the most important.

$\mathrm{Xi}$ used the phrase in his speech to emphasize the importance of ensuring people's livelihood for the full completion of the well-off life. “天地” (heaven and earth) and “黎民” (common people) are both missing concepts in the cultural background of the target language, in which “天地” originally refers to the natural world or society. In order to make the target readers, namely the readers with English cultural background understand and accept it and to convey the wisdom of Chinese leaders in governing the country and to promote core socialist values, $\mathrm{Xi}$ chose to reduce the broader concept of "heaven and earth" to "country" in translation.

Example 4 如果任由这些问题曼延开来, 后果不堪设想, 那就有可能发生毛泽东同志所形象比喻的霸王别姬了。

If we allow these problems to spread like weeds, the consequences will be disastrous, and the tragedy of Farewell
My Concubine, which Mao Zedong used as a metaphor for losing power, may come true.

According to Collins Advanced Learner's English Dictionary, "concubine" refers to a woman who lived with and had a sexual relationship with a man of higher social rank without being married to him in former times. While“霸王别 姬”tells a story about the overlord Xiang Yu who was defeated in the battle with the Emperor Han for the feudal ruling power and had to bid farewell to his beloved lady on the eve of breaking through. Obviously, this term "concubine" is of negative meaning which is absolutely contrary to the intention of the speaker. Due to the lack of information of the linguistic form itself and the background of the expressions with strong historical and cultural implications, the translator has applied “concubine" to translate “姬”. In the view of the writer, "concubine" is not the proper term for the translation of “姬” in such a context; "Farewell My Love" is hence proposed to enhance its transmission.

Example 5 要以燕子垒窝的恒劲、蚂蚁啃骨的㓞劲、老 牛爬坡的拼劲, 坚持不解, 攻坚克难, 善作善成。

Chinese language boasts the splendor of rhetoric, while English advocates on conciseness and logicality. This example well showcases the rhetoric features of Chinese language with the use of 燕子垒窝(swallows build nests), 蚂蚁啃骨(ants gnaw on bones) and 老牛爬坡(old oxen climb hills) that all indicate "diligence". However this cultural connotation is lacking in English language, thus the target readers will be confused if they are literally translated. So to make the sentence more concise and help the target readers fully understand the determination and perseverance of CPC in fighting corruption, the sentence is rendered into "We must persevere and solve them one by one, till all are addressed."

\subsection{Context and Translation}

In the process of communication, the communicator, language and context present a kind of co-occurrence or coexistence. In order to achieve the goal of successful communication with the readers, the translator needs to consider the cognitive context of the original work and the readers. Context greatly affects the translator's choice of language, so the translator must grasp the psychological, cultural, thinking mode and other contextual factors in order to best analyze and convey the original discourse. In order to achieve the goal of communication successfully, the translator is supposed to have enough knowledge about both language and context. It is not difficult to see that translation involves a very complicated pragmatic process. This process or activity shows a presence or coexistence relationship between two things. In other words, the communicator must follow a certain rule in the use of language, otherwise, communication cannot be successful; in order to achieve their communication purpose, the communicators must choose a certain context. In translation, the speaker constantly chooses the relevant context with his or her own communicative purposes. In this process, many cognitive systems such as knowledge, reasoning and memory need to be activated and at the same time factors like social skills and social practice are also 
involved.

Concerning this point, the use and the translation of metaphorical expressions in diplomatic discourses can be taken as appropriate examples. Metaphorical expressions are frequently applied in political discourses nowadays and to some extent have become a sparkling feature of political speeches. The readers are supposed to figure out the implied meaning of the metaphorical expressions if they want to understand the real intention of the speaker. Since the connotations of the metaphorical expressions are dependent on the contexts, the translator should have a proper grasp of the context of the source language, including the situational context and the cultural or historical context. For instance, the previous study of the writer found out that “牛鼻子”has been used in The Governance of China II for more than 5 times [14]. This expression originally refers to the nose of an ox which sounds not special at all. However, once the translator knows about the cultural background of this expression, he can accurately get the metaphorical meanings of it when it is used in different contexts. Since ancient China, ox has played a very significant role in the agricultural development of the society. In Chinese people's eyes, it stands for hard-working spirit, strength, integrity, wealth and fearlessness. The nose naturally is an essential part of an ox. The nose of an ox is undoubtedly applied to refer to something important as in the following examples in which it has been respectively translated into "critical problems" and "the key".

Example 6 在推进四个全面的过程中, 我们既要注重总 体谋划, 又要注重牵住“牛鼻子”。

In implementing this strategy, we should attend to both general planning and specific, critical problems.

Example 7 抓住了创新, 就抓住了牵动经济社会发展全 局的“牛鼻子”。

Innovation is the key to driving overall social and economic development.

Additionally, the thinking pattern of Chinese differs from that of English native speakers. Chinese tends to emphasize concreteness while English native speakers have a preference for abstract thinking. When translating from Chinese to English, it is easy for the translator to speak in the Chinese thinking way while under the cloak of English language, which makes it difficult or impossible for native English speakers to understand the meaning conveyed [15]. Thus, it is more acceptable that concrete concepts are generalized and abstracted in translation as shown in example 8. “衣食住行” has not been literally translated into "food, clothing, shelter, and transportation" but understood as a whole term to refer to the basic necessities in people's life, which caters for the thinking pattern of the target readers.

Example 8 老百姓的衣食住行, 社会的日常运行, 国家 机器的正常运转, 执政党的建设管理, 都有大量工作要做。

There is a tremendous amount of work to do in meeting the people's daily needs, ensuring the smooth running of society and the normal functioning of the state apparatus, and building and managing the governing party.

\section{Conclusion}

The pragmatic triadic relation mode provides a new perspective for the study of political discourse translation. The translator, language and context interact with each other in the translation process. The translator's subjectivity dominates his understanding of the source language and his use of the target language, which is reflected in his consideration of all levels of language. The translator's full grasp of context is the basis of the translator's subjectivity and creativity. The translation of specific terms with peculiar linguistic characteristics and profound cultural connotations is based on the translator's own understanding of the original text, respect for the characteristics of the source language, and adherence to the rules of the target language. The original situation and context can be reproduced through individual thinking mode to enable readers to obtain the maximum of cross-cultural experience and spiritual resonance.

\section{Acknowledgements}

The author wishes to acknowledge the support from the project "English Language and Literature", a Key Program in Guangdong Province, the project "A Study of Pragmatic Translation Strategies for Xi Jinping's Political Discourse" (Project Code: 2019GZGJ205) and the team project of South China Business College "The Characteristic and Cross-cultural Translation of Diplomatic Discourses of China" (Project Code: 2019-42).

\section{References}

[1] Xi J. P. (2014). The Governance of China (I) [M]. Beijing: Foreign Languages Press.

[2] Xi J. P. (2017). The Governance of China (II) [M]. Beijing: Foreign Languages Press.

[3] Xi, J. P. (2020). The Governance of China (III) [M]. Beijing: Foreign Languages Press.

[4] Kopytko, R. (1998). Relational Pragmatics: Towards a Holistic View of Pragmatic Phenomena [J]. Studia Anglica Posnaniensia, (33): 195-211.

[5] Kopytko, R. (2001). From Cartesian towards non-Cartesian Pragmatics [J]. Journal of Pragmatics, (33): 783-804.

[6] Kopytko, R. (2003). Relations in Pragmatics: a Theoretical Introduction [J]. RASK, (18): 93-114.

[7] Mo, A. P. (2002). Pragmatic Translation and Contextual Relevance [J]. Journal of Hengyang Normal University (Social Science), (3): 113-117.

[8] Lyons, J. (1977). Semantics [M]. Cambridge: Cambridge University Press.

[9] Newmark, P. (1982). An Approach to Translation [M]. Pergamon Press Limited.

[10] Yuan H. (2019). A Study on Ternary Relations in Translation Contextualization [J]. Journal of the Open University of Guangdong, (28) 1: 58-63. 
[11] He Z. R. (2015). The Conversion of Conceptual Structures in Pragmatics-oriented C-E Translation [J]. Journal of University of Science and Technology Beijing (Social Science Edition), (31) 6:1-6.

[12] Verschuren, J. (1999). Understanding Pragmatics [M]. London: Edward Arnold.

[13] Kolln, M. and Gray, L. (2013). Rhetorical Grammar: Grammatical Choices, Rhetorical Effects [M]. Boston: Pearson Education, Inc.
[14] Chen Y. L. (2020). Cognitive-Pragmatic Strategies for English Translation of Colloquial Metaphors in Political Discourse [J]. International Journal of Applied Linguistics and Translation, (6) 3: 89-95.

[15] Li M. and Li S. Y. (2018). Problems in Translating Chinese Political Discourse into English [J]. Fudan Forum on English Languages and Literature, Spring162-169. 